\title{
Carne(ar), no passado e no presente: hábitos e práticas alimentares entre descendentes de imigrantes alemães
}

Graciela Froehlich INTRODUÇÃO

$\left(U_{n} B\right)$

A carne faz parte do cardápio dos mais diversos grupos e aparece nas mesas diariamente com diferentes preparos, cheiros e sabores. Comumente reflete-se sobre ela, no que diz respeito ao seu gosto e qualidade, no momento de sua escolha ou quando é servida.

Ao nos depararmos com a carne, na forma em que é vendida nos supermercados e nos açougues, em pedaços ou cortes com nomes específicos, raramente nos perguntamos a respeito de sua origem, ou mesmo se aquele alimento, algum dia, já foi um animal vivo. Pedimos chuleta, pernil, lombo e costela, enquanto o animal que originou esses pedaços já foi há muito esquecido.

No entanto, em que pese a afirmação acima refletir sobre uma prática usual, ela não pode ser generalizada, uma vez que encontramos, entre diversas famílias que vivem no campo (e mesmo nos arredores de centros mais urbanizados) o costume de criar os animais para servir de alimento. Nestes casos, seu abate é realizado no ambiente doméstico, pelos próprios membros do grupo familiar. É esta prática, chamada de carneada, em que ocorre a passagem animal-alimento-comida, o foco das minhas atenções neste artigo.

O carnear compõe assim o quadro das reflexões que apresento aqui. Os dados discutidos tem origem no trabalho de campo empreendido durante o mestrado, em que pude participar de carneadas junto a colonos ${ }^{1}$ descendentes de imigrantes alemães do município de São Paulo das Missões, região noroeste do estado do Rio Grande do Sul. As transformações nas concepções e hábitos alimentares, bem como nas práticas de sociabilidade associadas ao carnear serão aqui referidos a dois momentos específicos. Um primeiro refere-se à criação - alimentação dos animais, espécies criadas, qualidade da carne -, e um segundo ao abate em si, onde são discutidas mudanças relativas aos pratos preparados a partir do porco, às técnicas e utensílios utilizados, à concentração de participantes e à distribuição de carnes². 
A alimentação, sob a perspectiva aqui considerada, reveste-se de um caráter muito especial, uma vez que constitui também um comportamento eminentemente simbólico, que "revela repetidamente a cultura em que cada um está inserido" (Mintz 2001: 32). As diferentes formas de comer revelam as culturas dos diferentes grupos, e as concepções e classificações por eles estabelecidas nos informam acerca de suas visões de mundo, bem como de sua própria organização social. O comer está diretamente relacionado à sobrevivência biológica do homem; trata-se de um ato vital, sem o qual a vida não é possível (Maciel 2001). O comportamento relativo à comida, no entanto, permite-nos adentrar no universo dos símbolos, da cultura, na medida em que se trata não apenas de um comportamento instintivo, mas de processos mediados por códigos culturais.

\section{OS COLONOS TEUTO-BRASILEIROS, A CARNE E A CARNE DE PORCO}

O município de São Paulo das Missões, de colonização germânica, localiza-se na região noroeste do Rio Grande do Sul. Fundado no ano de 1966, o município conta, atualmente ${ }^{3}$, com 6.364 habitantes. A agricultura e a pecuária leiteira são as principais atividades econômicas de seus habitantes. O início do povoamento de seu território remonta ao ano de $1910^{4}$, quando colonos residentes nas Colônias Velhas, como São Leopoldo e Dois Irmãos, e também as cidades de Ivoti, Santa Cruz do Sul, Estrela e Lajeado partiram de suas localidades de origem em busca de novas terras. Tal processo, chamado por Roche (1969) de enxamagem ${ }^{5}$, promoveu a colonização da região do Alto-Uruguai e das Missões, onde se situa o município.

Os colonos-camponeses teuto-brasileiros residentes em São Paulo das Missões têm no porco - mais precisamente em sua carne e derivados - uma fonte básica de alimentação. A criação deste animal foi praticada desde o início da colonização: "inicialmente formavam pequenas lavouras de fumo e feijão, também um pouco de mandioca e arroz. Havia igualmente pequenas criações de suínos, mas destinava-se apenas para a sua subsistência" (Nedel s/d: 46). Com o tempo, a criação foi incrementada com o estabelecimento de granjas, também chamadas localmente de chiqueirões:

com o passar dos tempos começaram a surgir os criadores de suínos. A criação era em grande escala, e quanto mais gordo o porco, melhor, pois na época a banha tinha muito valor. Quando o porco era bom, era possível comprar um "fusca" com o valor da venda duma carga de porcos (Nedel s/d: 39).

Em Fazenda Lohmann, localidade do Vale do Taquari, Rio Grande do Sul, (cf. Menasche \& Schmitz 2007), o negócio também era a banha ${ }^{6}$. A carne, comparativamente ao valor de mercado que a banha possuía, acabava por ficar em segundo plano, uma vez que a sua venda proporcionava a compra de produtos que não fossem fabricados na propriedade. A banha também desempenhava o importante papel de conservar a carne do porco abatido, além de ser largamente utilizada na cozinha, sem esquecer-se de seu uso medicinal ${ }^{7}$. Cumpria assim a função de refrigerador, conservando a carne em um tempo em que não existia energia elétrica, ou ainda quando aparelhos de refrigeração eram inacessíveis financeiramente a boa parte da população. A carne era frita e armazenada em 
latas cheias de banha, sendo utilizada no dia a dia até que acabasse. Em lugar do óleo vegetal hoje consumido, era a banha de porco que servia de base às frituras. Ela estava presente desde o café da manhã, quando o pão com banha fornecia a energia necessária para o trabalho na lavoura, para onde também era levada, servindo de merenda ${ }^{8}$. Configura-se, assim, a comida forte (Woortmann, K. 2004), que sustenta o trabalhador nas lidas com os animais e na roça. Ela também entra na composição da massa desse mesmo pão, o que sugere a versatilidade de seu uso.

Os porcos criados nesse período eram escuros, os chamados "tipo banha", e eram engordados até produzirem o máximo de gordura. Uma mudança considerável passa a ocorrer a partir do ano de 1937, com a proibição do abate doméstico de porcos para a exportação da banha e, especialmente, a partir de 1940, com a ocorrência da Peste Suína Clássica no Brasil (Terhorst \& Schmitz 2007: 103). Foi o período em que os óleos vegetais começaram a se apresentar com maior intensidade no território nacional e em que a gordura animal passou a ser apontada como um grande vilão dos problemas cardíacos (Op. Cit.: 108).

O cultivo da soja, que dá origem ao óleo vegetal, largamente incentivado pelo Estado, também foi responsável pela mudança no tipo de suínos criados, substituindo, paulatinamente, o porco "tipo banha" pelo "tipo carne", ou branco. Nesta transição, os hábitos alimentares também se alteraram. Os óleos vegetais passaram a ocupar espaço cada vez maior entre os próprios colonos e, sobretudo, entre os habitantes da cidade. Nas carneadas de que participei, os porcos abatidos eram brancos, do "tipo carne". No entanto, as narrativas afirmam que a sua carne não tem o mesmo sabor dos porcos escuros, "tipo banha". A opção pelos primeiros dá-se em função de aqueles fornecerem maior quantidade de carne, visto que a banha é consumida e utilizada em uma escala muito menor nos dias de hoje.

Do período glorioso da suinocultura, uma expressão chegou aos dias atuais. Dentre os muitos aromas perceptíveis ao perpassar pelas estradas do município, um dos que mais se destaca é o “cheiro de dinheiro". É assim que muitos se referiam ao poderoso aroma oriundo dos chiqueiros de porcos. Coloco o verbo no passado, porque hoje essa expressão geralmente vem acompanhada de um "antigamente", ou seja, quando a criação de porcos ainda era um negócio lucrativo para muitas famílias. O dizer de Antonio reflete o decréscimo na criação de porcos:

"antigamente todo mundo criava pelo menos um porquinho pro consumo da família, mas hoje em dia eles preferem comprar. Hoje em dia a ração também está muito cara, não vale mais a pena pro colono...."

Duas questões merecem ser apontadas aqui. A primeira diz respeito à centralidade da carne (tanto de porcos como de bois) no prato e na dieta desses colonos. A segunda refere-se à valorização e ao desejo da carne consumida ser de um animal conhecido - preferencialmente criado e cuidado pela família.

Entre os colonos de São Paulo das Missões, a carne está presente diariamente, ainda que os melhores cortes sejam guardados para ocasiões determinadas, como o almoço de domingo, dias de visita ou mesmo nas carneadas, quando se consome carne fresca e, geralmente, pedaços considerados de alta qualidade 9 . Apesar de o congelador oferecer uma possibilidade de armazenamento que permite uma conservação considerável das características do alimento, conforme os relatos, ela não tem o mesmo sabor depois de refrigerada. 
As carnes de porco e de boi disputam a centralidade na mesa dos colonos. Nas refeições do cotidiano, escolhe-se entre uma ou outra, enquanto em acontecimentos festivos ambas são oferecidas aos convidados. Muitos são enfáticos ao afirmar que a carne de porco é a preferida, mas que não se alimentam dela diariamente em função de ser mais gordurosa e, portanto, prejudicial à saúde. A carne bovina, que antes constituía raridade no prato dos colonos, hoje pode ser guardada no freezer e consumida pela família por vários meses. O mesmo observa Ramos (2007) entre agricultores de Maquiné: "a presença de carne nas refeições é hoje frequente, muito em função da oferta de carnes ser mais abundante, o que decorre, dentre outros fatores, da chegada da energia elétrica em suas residências. Hoje, podem armazenar um boi inteiro no freezer" (p.89 grifos da autora).

A carne é assim o prato principal, a comida, por excelência, fornecedora da "força"10 necessária para o trabalho pesado do dia a dia. Entre os acompanhamentos ${ }^{11}$ mais freqüentes estão a batata, a mandioca, o macarrão, o arroz o feijão e saladas, tomate, repolho, alface, beterraba. A maior parte desses alimentos é cultivada na própria propriedade, excetuando-se o arroz, adquirido nos supermercados locais.

Pela importância atribuída à carne, sua qualidade deve ser inquestionável. Para tanto, nada mais adequado do que a produção doméstica do animal a servir de alimento: "essas carnes que não se sabe de onde vêm..."12. 0 desconhecimento da origem desperta uma sensação de insegurança relacionada principalmente à administração de produtos químicos artificiais presentes em remédios e hormônios, bem como daquelas substâncias presentes nas rações industrializadas.

Os animais devem, portanto, ser criados de forma "natural", "limpa". A limpeza está assim relacionada à ausência de produtos químicos artificiais na criação, enquanto o impuro se reflete na administração de medicamentos e substâncias quimicamente elaboradas. Para tanto, a base da alimentação dos porcos é constituída da lavagem, uma mistura composta de vegetais colhidos na propriedade, restos de comida e uma mistura de farelos. A dieta dos porcos varia conforme as preferências dos criadores, mas pode-se resumi-la da seguinte forma: pela parte da manhã e à tardinha, os porcos são alimentados com uma mistura de milho, farelos de soja e arroz e sal mineral, sendo os farelos e o sal adquiridos junto a agropecuárias do município; ao meio-dia, é servida mandioca e "algum verde". Para deixar esta mistura mais molhada e gostosa, é adicionada a água com que são lavados os tarros de leite, ou ainda o leite que sobre do consumo familiar: "Eu misturo com leite, porque os porcos gostam, fica molhado. Os restos de comida que sobram da mesa também damos pros porcos, de lavagem".

Uma carne de boa qualidade, tal como é desejada e perseguida pelos colonos, começa assim na sua criação. Esta deve ser levada a cabo pelos meios mais naturais possíveis: alimentação natural e tratamentos também naturais. Isso envolve a não administração de substâncias químicas aos animais - tanto contidas em alimentos como em medicamentos, o que estaria na raiz de uma carne de má qualidade. 


\section{COLOCANDO A MÃO NA CARNE}

Nos parágrafos que seguem procuro descrever as carneadas a partir de duas ocasiões em que pude testemunhá-las quando de meu trabalho de campo. Como poderá ser visto, as técnicas empregadas nessa morte são diferenciadas, variando conforme as famílias que realizam o abate. Algumas características se assemelham, mas, de modo geral, é bastante arriscado traçar um padrão único para esses eventos.

Como primeira observação, saliento que não há uma regra estrita a ser seguida no que diz respeito à sazonalidade e ao horário para as carneadas acontecerem. Existe uma preferência de carnear no inverno, pois a carne conserva-se melhor nos dias de frio. Ainda assim, elas acontecem tanto nas épocas de frio quanto no verão, variando conforme a necessidade de carne da família, de algum acontecimento especial (como as festas de comunidade ${ }^{13}$ ), de um casamento ou de um aniversário. Elas ainda podem acontecer tanto pela manhã quanto à tarde e à noite, embora neste último período sejam bastante raras. Sua duração varia conforme as iguarias que são preparadas - mais longas quando são preparados o salame e morcilha, por exemplo. Quando iniciam pela manhã, em torno das sete horas, geralmente estendem-se até por volta das catorze horas, intervalo no qual ocorrem o abate propriamente dito e o armazenamento da carne. Quando acontecem pela parte da tarde, iniciam após o almoço, e o marco temporal de seu fim é a hora em que começam os trabalhos de tirar o leite das vacas e alimentar os outros animais - o que, no inverno, se dá por volta das dezessete ou dezoito horas.

$\mathrm{O}$ abate ocorre nas áreas próximas aos chiqueiros, aos currais e aos galpões destinados ao armazenamento dos utensílios utilizados nas lidas com o gado e na lavoura. A higienização dos utensílios e instrumentos a serem utilizados geralmente é feita pelas mulheres. Entretanto, se no fluxo dos acontecimentos se faz necessária a lavagem de algum instrumento e as mulheres estão ocupadas com algum outro afazer, os homens procedem à limpeza.

Uma vez preparado o ambiente da carneada, matar o animal é o próximo passo. As técnicas empregadas variam. Pude testemunhar duas: insensibilização com o machado e sangria direta. Na primeira, antes da sangria, o matador utiliza-se do dorso de um machado para atingir a fronte do animal e insensibilizá-lo. Uma segunda consiste em amarrar o animal e fazer a sangria diretamente, sem algum tipo de insensibilização anterior.

O matador deve fundamentalmente conhecer o ponto certo onde furar o animal, e ter prática na função. São duas características reconhecidamente importantes. O porco deve já ser derrubado para o lado correto, visando acertar a artéria principal. $\mathrm{O}$ conhecimento para tanto passa de pai para filho: aprende-se inicialmente observando e participando das carneadas, para posteriormente assumir o posto de matador. Como no campesinato estudado por K. e E. Woortmann (1997), no Sergipe, em inícios da década de 1980, o aprendizado do trabalho dá-se no próprio trabalho, onde a transmissão de conhecimento envolve também valores e construções de papéis (p.11).

Pela prática e perícia com que determinadas pessoas realizam a função de matadores, o "dono do porco" pode ser substituído por algum matador reconhecido, geralmente seu parente. Nesse caso, o matador traz consigo a faca com que irá matar o animal. Ela não é necessariamente uma faca passada de geração a geração, guardada como relíquia. Pode ser nova, adquirida nos supermercados ou outros comércios, e é, muitas vezes, também utilizada 
para outros fins. No entanto, como já foi dito, o matador utiliza a sua faca, e não a do anfitrião. Ela caracteriza-se por ser mais pontiaguda que as facas normais para o corte de carne, devendo ser muito bem afiada. Como disse Paulo, "ela é especial pra isso, mas não é usada só pra isso".

Uma boa morte significa uma morte rápida, com poucos grunhidos e espasmos. Isto se deve a dois motivos, que parecem andar lado a lado. Há uma preocupação com o sofrimento do animal, bem como com a qualidade da carne, que fica prejudicada em caso de possíveis ferimentos e hematomas decorrentes das pancadas sofridas.

$\mathrm{O}$ ato de matar o animal é geralmente uma tarefa masculina. No entanto, fui informada de que algumas mulheres realizavam essa tarefa, sendo reconhecidas por esse fato. O que pude perceber é que aqui as restrições com relação às mulheres ou são mais veladas, ou, de fato, as mulheres assumem posições que, em outros contextos, são tradicionalmente masculinas. Nos trabalhos de Nogueira (2004), Wedig (2009) e Ramos (2007) nota-se que a simples presença feminina no momento da morte pode ser prejudicial: sendo a mulher demasiado afetiva, seu olhar de piedade poderia alongar a morte do animal, prolongando seu sofrimento ou ainda "sujando" sua carne.

Logo após a morte do animal, a primeira providência é lavá-lo. Feita a lavagem, o porco é pendurado por ganchos, pelas patas ou cabeça. O couro é então retirado, isoladamente, ou juntamente com a camada de gordura, cortando-se rente à carne. Este trabalho é realizado por homens e mulheres. Posteriormente as vísceras são retiradas com as mãos e dispostas em uma bacia de alumínio. Alguns órgãos serão utilizados na alimentação, especialmente rins, coração, fígado e tripas. O consumo destes órgãos varia conforme a preferência das famílias. Muitos não consomem os rins, por exemplo, porque estes trariam as impurezas filtradas da urina. Outros o acrescentam ao torresmo, juntamente com o coração. As tripas são lavadas para acondicionar a morcilha e o salame. Muitas vezes, elas são congeladas e utilizadas quando do feitio dessas iguarias posteriormente.

O esquartejamento é a etapa seguinte. Para esse processo utiliza-se um picador elétrico ou uma serra manual para cortar os ossos. As partes mais macias são cortadas com a faca. É nesse momento que são "criados" a costela, o lombo, cortados os pernis em pedaços de tamanho suficiente para serem armazenados no congelador. O esquartejamento é considerado por Vialles (1998) como uma desanimalização. Ele consiste em eliminar sucessivamente as pernas, a cabeça, as vísceras torácicas e abdominais, bem como o couro, para obter uma carcaça própria aos cortes de açougue, nos quais o animal já se encontra sob a forma de carne. Para a autora, o paradoxo dessa morte está no seu resultado: ela não produziu um cadáver. Esse paradoxo está ligado a uma tradição secular, segundo a qual animais mortos - em razão de causas naturais - não são considerados comestíveis. Assim, somente a carne de animais "matados" é comestível. Retomando a noção de que as qualidades dos alimentos são transmitidas ao comedor, no caso dos animais "matados" as qualidades transmitidas são aquelas de quando este estava vivo - ao contrário dos cadáveres, que transmitiriam sua qualidade doente à carne e, por conseguinte, a quem dela se nutrisse.

Os cortes são separados também conforme o modo de fazer - se irão para a panela, ou assados nos churrascos. $\mathrm{O}$ esquartejamento do animal é executado essencialmente pelos homens. Enquanto isso, as mulheres ocupam-se das chamadas miudezas, da limpeza e separação das vísceras, da lavagem dos utensílios e da preparação dos acompanhamentos do churrasco. 
No entanto, os papéis desempenhados por homens e mulheres não possuem uma determinação tão rígida quanto um primeiro olhar poderia sugerir. A determinadas atividades parecem estar reservados papéis estritamente masculinos ou femininos, como é o caso de matar e lavar os utensílios. Em campo, a lavagem dos utensílios foi feita essencialmente pelas mulheres; em alguns momentos, quando a urgência forçava a realização desta atividade pelos homens, era para a higienização de alguma faca que precisavam naquele momento.

Ainda que existam mulheres que matem, estas executam tal tarefa na ausência dos homens; das duas mulheres de que tive notícia, uma é viúva e a outra se encontra com o marido enfermo. Tais casos parecem ser as exceções que confirmam a regra. Essas situações em que a mulher atua como "matador" podem ser entendidas como situações críticas, em que a mulher ocupa interinamente uma função que é essencialmente do homem, chefe de família (Woortmann, E. \& Woortmann, K. 1997). Ela atua como substituta dele, sendo também a sua habilidade reconhecida como masculina: "mas ela mata que nem um homem!". Conforme E. Woortmann. e K. Woortmann. “poder-se-ia dizer que, se o homem é o responsável pela direção, a mulher, nesses casos, está responsável por ela" (1997: p.46 grifos dos autores).

Uma vez esquartejado o animal e a gordura colocada no tacho para o feitio do torresmo, tem início o componente festivo das carneadas. Ele é marcado pela presença de música e bebidas alcoólicas (cerveja ou cachaça). A partir desse momento, o ambiente torna-se mais descontraído, os trabalhos menos pesados, as conversas mais animadas.

\section{TRABALHO, FESTA E RECIPROCIDADE}

O dia da carneada apresenta um duplo caráter, em que trabalho e festa encontram-se combinados. Há trabalho a ser feito; no entanto, trata-se de um trabalho diferente daquele exercido no dia a dia nas lidas da lavoura. Familiares e amigos reúnem-se para a realização de uma atividade que, pelo incremento do churrasco, da cerveja e da boa companhia, acaba por assumir ares de comemoração.

Não resta dúvida de que o dia da carneada é um dia de trabalho: diversas vezes me foi falado que "carnear dá trabalho". Entretanto, é um trabalho esporádico, que se reveste de um caráter diverso do trabalho do cotidiano. Nesse dia também os outros afazeres permanecem: é preciso alimentar o gado, as galinhas, os porcos, tirar o leite das vacas, limpar os currais e chiqueiros. $O$ evento da carneada exige que se rearranje o tempo para que esses trabalhos todos também sejam feitos, além daqueles relacionados à carneada.

Nesse universo, aqueles visitantes que chegam para a carneada vêm ajudar - ajudar a trabalhar na realização das atividades acima descritas. O trabalho, na sua modalidade ajuda, é recompensado com ajuda na carneada seguinte e carne: a troca de ajuda e carne marca a reciprocidade ${ }^{14}$ embutida nas carneadas. A noção de ajuda é fundamental para entendermos a sistemática da troca de trabalho nas carneadas. Naquelas das quais participei, os ajudantes, sem exceção, eram familiares, irmãos, sobrinhos e filhos. É realizada uma troca, que implica ao 
mesmo tempo em retribuição na forma de carne e de ajuda na carneada do outro. Paulo e Solange, por exemplo, estabeleceram, como disseram, um "sistema" com Hugo, cunhado de Paulo. Por meio deste sistema, quando um animal é carneado na residência de Paulo Hugo vem ajudar - muitas vezes acompanhado de sua esposa. Da mesma forma, quando Hugo carneia, é Paulo quem vai até sua casa. Quem chega para ajudar sempre sai com algum pedaço de carne. Cláudia, que ajudou na carneada na casa de Antonio e Verônica, levou para sua casa um pernil ${ }^{15}$, que, ao lado do lombo e da costela, está entre os cortes mais valorizados e apreciados. Um corte de costela foi o que levou para casa Seu Hugo, na carneada com Solange e Paulo.

A divisão dos cortes é feita conforme a preferência daqueles que vêm ajudar ${ }^{16}$, sendo que a quantidade não é pesada ou medida - não vi qualquer balança no ambiente da carneada. O visitante pode ainda levar para casa um pedaço que não é valorizado, no sentido financeiro da palavra, mas pelo qual particularmente tem muito apreço - como é o caso do fígado, patas e cauda.

Cria-se assim um círculo em que, conforme afirma Paulo, "não se mede, não se olha e não se cobra". Essa troca, ou "sistema", nas palavras de Paulo, não se dá, entretanto, como uma troca de ajudas ou favores entre indivíduos. A origem familiar é extremamente importante nesse contexto, o que nos leva a deduzir, partindo de K. Woortmann, que a troca se dá mesmo entre famílias ou entre pais de família, enquanto pessoas morais, e não enquanto indivíduos (1990: 36-37) - famílias enquanto indivíduos coletivos e entidades hierárquicas, e pais de família que encarnam essas entidades.

O componente festivo das carneadas tem um momento para começar: quando o torresmo ${ }^{17}$ é colocado no tacho e se inicia a fritura. Nesta hora, o trabalho mais "pesado" já foi feito, e as atividades a que todos se dedicam são mais "leves"18. Os convivas sentam-se e cuidam em mexer com frequência o torresmo, que pode ser o prato principal servido na carneada, acompanhado de cerveja.

Entretanto, quando é feito o churrasco, é ele quem ocupa o lugar central, e é à volta dele que se organizam os presentes. Mais do que apenas "comer o churrasco", o "fazer um churrasco" - que envolve um grupo social é caracterizado enquanto um ritual de comensalidade e partilha. Assim, ele não é considerado comida de dia de semana, mas está reservado às ocasiões especiais e festivas, nas quais insiro as carneadas, representando:

[...] sempre um momento especial, fora do mundo cotidiano do trabalho, das refeições apressadas, um momento de reencontro e de convivência entre participantes de um grupo e, assim como outras refeições em grupos, ele serve para reforçar os laços pela partilha da comida (Maciel 2010:101).

O churrasco é, desse modo, juntamente com outros elementos, um dos vetores festivos das carneadas. Não é exagero reiterar a sua posição de prato favorito para as ocasiões comemorativas: ele é o prato preferencial a ser oferecido ao estrangeiro, sinônimo e provedor de prestígio. Nesse sentido, ao saborear dos mesmos pratos, compartilham-se gostos e experiências. 
A carneada torna-se assim um evento que proporciona a reunião de familiares e amigos em torno de um objetivo comum - auxiliar nas atividades de abate de porcos - e, posteriormente, compartilhar do momento de apreciar os resultados daquele trabalho, comendo juntos. Nas narrativas acerca das carneadas do passado, o caráter festivo também é evidente: "quando se carneava um porco era uma festa! Um dia diferente, atípico, em relação aos outros" (Kaspary 2010: 58). Esta, entre outras falas, revela que essa prática tem se transformado ao longo dos anos, e é acerca destas mudanças que discorro neste espaço final.

Na memória, encontra-se a lembrança dos tempos em que as carneadas eram mais frequentes, os filhos mais numerosos e o porco "valia a pena" como fonte de renda. Neste tempo, também, as carneadas contavam com o envolvimento de um número maior de pessoas - famílias mais numerosas - entre as quais a carne trocada regulava um sistema que, na ausência dos métodos modernos de conservação possibilitados pelo advento da energia elétrica, proporcionava o abastecimento de carne fresca para as famílias que se envolviam na carneada.

A chegada do freezer e da geladeira teve um impacto decisivo nesse contexto, alterando radicalmente os padrões alimentares e a configuração das carneadas. A possibilidade de armazenamento de carne por meses juntamente com o decréscimo no tamanho das famílias - possibilita que se mate um animal em intervalos de tempo maiores e com uma mão de obra reduzida, visto que também muitas das iguarias deixaram de ser preparadas a cada carneada. Elas permanecem, no entanto, como comidas apreciadas e socialmente valorizadas.

A mesa, nos pratos preparados a partir do porco, também se modificou no decorrer dos anos. Nos relatos sobre as carneadas de antigamente, diversos foram os exemplos de iguarias preparadas a partir deste animal: salada de estômago, morcilha branca, morcilha preta, charque de porco, toucinho, torresmo, salame. No entanto, nas carneadas em que participei somente o torresmo foi preparado. As justificativas para isto foram das mais variadas: o tempo de preparo, a mão de obra despendida, o paladar que se "assusta" frente a esses alimentos gordurosos foram algumas das razões apontadas para a diminuição do preparo dessas iguarias. O preparo de embutidos não se dava somente em função do gosto e apreço por esse tipo de comida: a defumação constituía-se em uma forma de conservação da carne, que podia assim ser comida na forma de salames, morcilhas e charques nas semanas subsequentes à carneada.

Tais mudanças demonstram novamente que a cozinha e a identidade associada a ela não podem, de forma alguma, ser concebidas de maneira estanque. Longe de constituir um corpo de conhecimentos e práticas cristalizadas no tempo e no espaço, tais mudanças reforçam o caráter dinâmico dos processos culturais. Mais que simplesmente matar um animal para comê-lo, a carneada torna-se um momento de reunir familiares, reafirmar valores e (re)construir saberes e práticas em torno da alimentação.

Graciela Froehlich é Doutoranda em Antropologia Social na Universidade de Brasília (Unb). 


\section{NOTAS}

1 Segundo Seyferth (1993), o termo colono, na forma com que o utilizo aqui, refere-se não apenas a uma ocupação econômica, mas a componentes étnicos e morais. Trata-se de uma noção construída ao longo do processo histórico relacionado à colonização de origem europeia a partir do significado oficial do termo e da sua apropriação por parte dos camponeses (Bauern) emigrados e aqui assentados.

2 Entendo que a transformação do animal em alimento inicia-se já no período de sua criação. Os cuidados com o ambiente de seu crescimento, sua alimentação e administração de medicamentos - ou não - são elementos evocados na caracterização de uma carne de qualidade.

3 Dados do Censo Demográfico do IBGE (2010).

4 Neste período, a imigração oficial, patrocinada pelo Estado, já havia enfraquecido. Foram empresas colonizadoras que assumiram a responsabilidade de assentar os colonos nas terras "devolutas", regiões preteridas anteriormente seja pela sua distância em relação à capital, seja pela qualidade de suas terras (Woortmann, E. 1995). O Deutscher Bauernverein (Associação Alemã de Camponeses) foi a empresa que estabeleceu os primeiros moradores do município.

5 Como causas primeiras desse movimento migratório Roche (1969) aponta para o esgotamento das terras e o crescimento da população, somando-se a estes fatores, como motivos fatais, uma taxa de natalidade e técnicas incompatíveis com a estrutura agrária (p. 319).

6 A banha é extraída da camada de gordura do porco, que compõe parte considerável de seu peso. Para extraí-la, a gordura é picada em pequenos pedaços e frita por cerca de duas horas. Para finalizar, é separada dos cubos mais consistentes com a ajuda de uma prensa.

7 A banha é ainda utilizada por alguns colonos como cicatrizante no tratamento de feridas as mais diversas, bem como de queimaduras.

8 A merenda é a refeição realizada nos intervalos de trabalho na lavoura e também nas escolas, onde é servida no intervalo entre as aulas.

9 Entre os operários, K. Woortmann (2004) percebe a mesma preferência: "o almoço de domingo inclui sempre uma carne "melhor" - que pode, às vezes, ser um churrasco - ou um assado, ao invés de um cozido" (p.22).

10 Conforme K. Woortmann (2004), a qualidade de forte do alimento vem da sensação de saciedade que o mesmo proporciona.

11 À exceção das dietas vegetarianas e macrobióticas.

12 As carnes de origem desconhecida podem ser incluídas na categoria de Objetos Comestíveis Não Identificados - OCNI -, de Fischler (1995:210)

13 Chamadas de churrasco de confraternização, essas festas são organizadas pelos distritos rurais na sede do clube da comunidade, geralmente associadas a alguma igreja.

14 Reciprocidade na forma enunciada por Mauss (1974). Dos estudos clássicos de Cândido (1982) e Brandão (1981), e, mais recentemente, Sabourin (2009) a reciprocidade pode ser tomada como a característica mais marcante do campesinato brasileiro.

15 Naquelas de que participei, não pude sair de mãos "abanando". Um punhado de torresmo e fígado me foram presenteados nos momentos de despedida. Embora não possa dizer que tenha ajudado muito - apenas picava a gordura para o torresmo e mexia este enquanto estava no fogo - senti os presentes, de certa forma, como uma espécie de cortesia, um agrado para a visitante que desejava conhecer um pouco mais sobre aquela prática e aquelas pessoas.

16 No passado, era comum que se distribuísse um corte para determinados personagens considerados importantes da localidade, tais como o médico, o padre e o prefeito. Esta prática significava uma honra para quem doava. Era também uma forma de ser lembrado por tais figuras nos momentos de necessidade. Hoje isto já não acontece mais, e os entrevistados não puderam me relatar nenhum exemplo de alguma família que ainda procedesse de tal forma.

17 O torresmo está entre os subprodutos do porco mais apreciados, sendo produzido em todas as carneadas. Mais adiante discuto um pouco mais a respeito de outros subprodutos. 
18 Paulilo (1987) distingue o trabalho "leve" do "pesado" sob uma perspectiva de gênero. Ela percebe esta distinção em diversas regiões do país, desde estados do Nordeste até Santa Catarina, no sul do Brasil, e posso dizer que encontrei, ainda que de forma aproximada, a mesma distinção entre os agricultores de São Paulo das Missões. A qualidade de "leve" ou "pesado" para o trabalho encontra sua fundamentação não na natureza do trabalho em si, mas pelo sexo de quem o realiza: "leve" é o trabalho realizado por mulheres e crianças, e "pesado" é o trabalho de homens adultos (Paulilo 1987: 66-67; 70). 


\section{REFERÊNCIAS BIBLIOGRÁFICAS}

BRANDÃO, Carlos Rodrigues. 1981. Plantar, colher, comer. Um estudo sobre o campesinato goiano. Rio de Janeiro: Edições Graal Ltda.

CÂNDIDO, Antônio. 1982. Os parceiros do Rio Bonito: um estudo sobre o caipira paulista e a transformação dos seus meios de vida. São Paulo: Livraria Duas Cidades.

FISCHLER, Claude. 1995. El (h)omnívoro. El gusto, La cocina y El cuerpo. Barcelona: Editorial Anagrama.

IBGE. 2010. Cidades. Disponível em: http://www.ibge.gov.br/cidadesat/topwindow.htm?1. Acesso em: 20 de julho de 2010.

KASPARY, Pedro Hilário. 2010. “Cinquenta anos atrás”. In Köhler, Mirna (org.) Raízes: São Paulo das Missões, nossa missão, nosso futuro. Santo Ângelo: EDIURI.

MACIEL, Maria Eunice. 2001. “Cultura e alimentação ou o que tem a ver os macaquinhos de Koshima com BrillatSavarin?". Horizontes antropológicos 16: 145-156.

2010. “Uma cozinha à gaúcha”. In C. Brum, M. E. Maciel e R. Oliven (orgs.) Expressóes da Cultura Gaúcha. Santa Maria: Editora da UFSM.

MAUSS, Marcel. 1974. Sociologia e Antropologia. Volume II. São Paulo: Edusp.

MENASCHE, Renata \& SCHMITZ, Leila Claudete. 2007. "Agricultores de origem alemã, trabalho e vida: saberes e práticas em mudança em uma comunidade gaúcha". In R. Menasche (org.) A agricultura familiar à mesa: saberes e práticas da alimentação no Vale do Taquari. Porto Alegre: Ed. UFRGS.

MINTZ, Sidney W. 2001. “Comida e antropologia: uma breve revisão”. Revista Brasileira de Ciências Sociais 47(16): $31-41$.

NEDEL, Airton Moacir. s/d. São Paulo das Missões: teu passado é nossa história. Cerro Largo: Gráfica Lenz.

NOGUEIRA, Sandra. 2004. “Da Banca da matança aos enchidos: a festa e os rituais de transformação do porco em alimento". Mneme: Revista Virtual de Humanidades 9(5): 65-103.

PAULILO, Maria Ignez Silveira. 1987. "O peso do trabalho leve". Ciência Hoje 28(5): 64-70.

RAMOS, Mariana Oliveira. 2007. "A comida da roça" ontem e hoje: um estudo etnográfico dos saberes e práticas alimentares de agricultores de Maquine (RS). Dissertação de Mestrado. Programa de Pós-Graduação em Desenvolvimento Rural. Porto Alegre, RS: Universidade Federal do Rio Grande do Sul.

ROCHE, Jean. 1969. A colonização alemã no Rio Grande do Sul. Porto Alegre: Editora Globo.

SEYFERTH, Giralda. 1993. “Identidade camponesa e identidade étnica (um estudo de caso)”. Anuário Antropológico (91): 31-63. 
TERHORST, Karin Inês Lohmann \& SCHMITZ, José Antônio Kroeff. 2007. “De porco a suíno: história da suinocultura e dos hábitos alimentares associados aos produtos dela derivados entre agricultores do Vale do Taquari". In M. Renata (Org.) A agricultura familiar à mesa: saberes e práticas da alimentação no Vale do Taquari. Porto Alegre: Ed. UFRGS.

VIALLES, Noëlle. 1998. "Toute chair n'est pas viande. Mort et mise à mort dês animaux". Etudes Rurales 147-148: 139-149.

WEDIG, Josiane Carine. 2009. Agricultoras e agricultores à mesa: um estudo sobre campesinato e gênero a partir da antropologia da alimentação. Dissertação de Mestrado. Programa de Pós-Graduação em Desenvolvimento Rural. Porto Alegre, RS: Universidade Federal do Rio Grande do Sul.

WOORTMANN, E. 1995. Herdeiros, Parentes e Compadres: colonos do Sul e sitiantes do Nordeste. São Paulo: Hucitec; Brasília: Ed UnB.

WOORTMANN, K. 1990. "“Com parente não se neguceia": o campesinato como ordem moral”. Anuário Antropológico (87): 11-73.

2004. “O sentido simbólico das práticas alimentares". In Wilma M. C. Araújo (Org.) Anais do 1o Congresso de Gastronomia e Segurança Alimentar. Brasília.

WOORTMAN, Ellen \& WOORTMANN, Klaas. 1997. O trabalho da terra: a lógica e a simbólica da lavoura camponesa. Brasília: Ed. UnB. 
Carne(ar), no passado e no presente: hábitos e práticas alimentares entre descendentes de imigrantes alemães

\section{RESUMO}

O objetivo deste trabalho é refletir a respeito das transformações nos hábitos alimentares e nas práticas de sociabilidade entre colonos descendentes de imigrantes alemães do município de São Paulo das Missões, noroeste do Rio Grande do Sul, a partir da prática das carneadas. A experiência de campo e as narrativas acerca das carneadas constituem o terreno a partir do qual busco refletir acerca dos conhecimentos e valores embutidos nesta prática, bem como a respeito das mudanças percebidas pelos interlocutores, contadas a partir de suas memórias. As carneadas constituem um momento especial na transformação dos animais em alimento, reunindo familiares e amigos, fortalecendo os laços de reciprocidade e solidariedade. Para comer carne de qualidade, de acordo com a classificação local, não basta dirigir-se ao supermercado ou açougue. O animal que fornece carne à família é criado e abatido por ela própria, de acordo com conhecimentos e práticas também específicos.

PALAVRAS-CHAVE: Antropologia da Alimentação. Carneadas. Campesinato. Reciprocidade. Sociabilidade

To butcher, in the past and present: habits and eating practices among german immigrants.

\section{ABSTRACT}

The aim of this paper is to reflect about the changes in eating habits and sociability among settlers descendants of German immigrants in São Paulo das Missões, northwest of Rio Grande do Sul, by the practice of the carneadas. The fieldwork experience and the narratives about the carneadas constitute the ethnographic material from which I argument about the knowledge and values embedded in this practice, as well as about the changes perceived by the people and told in their memories. The carneadas constitute a special moment in the transformation of an animal into food, gathering relatives and friends, strengthening the bonds of reciprocity and solidarity. To have good meat, according to local rating, it is not only going to the supermarket or butcher shop. The animal that provides meat for the family is created and slaughtered by the own family in accordance with specific knowledge and practices as well.

KEY WORDS: Anthropology of food. Carneadas. Peasantry. Reciprocity. Sociability

Recebido em 31/05/2012

Aprovado em 28/08/2012 